\title{
A Study on Application of Educational Technology Instructional Design Model for Development of Consulting Methodology
}

\author{
Mun-Jeong Kang ${ }^{1}$, Sae -Hong $\mathrm{Cho}^{2^{*}}$ and Do-Sung Na ${ }^{1}$ \\ 'Department of Knowledge Service and Consulting, Hansung University, Seoul, Korea; \\ mjkang@talpiot.or.kr, dosna@hansung.ac.kr \\ 2Department of Computer Engineering, Hansung University, Seoul, Korea; chosh@hansung.ac.kr
}

\begin{abstract}
Objectives: Professional consulting is highly influenced by personal capabilities of consultants rather than standardized consulting methodologies. This study aims to suggest a method of developing and designing methodologies in different situations. Methods/Statistical Analysis: After developing and applying a Rapid prototype-based consulting methodology, a survey was conducted in order to evaluate its effectiveness and based on the result of FGI (Focusing Group Interview), the effectiveness, practicality and roles of development participants were analyzed. Overall composition and goal of consulting methodology was confirmed by the firm and preliminary application was performed in the first prototype. Evaluation on the second prototype was subject to firm employees and firm experts and evaluation on the third prototype was conducted subject to firm experts. Findings: The Rapid prototype model which is a type of user based Instructional System Design (ISD) researched in educational technology was applied in consulting sites to investigate the effects. Through analysis, design, development and evaluation steps for 3 months, satisfaction and effectiveness could be increased compared to the control group. Moreover, the important fact is that satisfaction and acceptance have been improved together in the perspective of mutual application by each step through various types of communication and sharing between firms and consultants. Therefore, it could be confirmed that overall consulting quality could be improved when consulting methodology is constructed and applied with the firm instead of applying standardized consulting methodology to firms. Improvements: It was confirmed that the Rapid prototype model can be effectively applied in developing future consulting methodologies that can be applied in firms. Also, required future assignments could be deducted through empirical research. Following this, it is expected that various methodologies can be developed in the process of developing consulting methodologies in earnest based on this research.
\end{abstract}

Keywords: Consulting Engineering, Consulting Methodology, Consulting Quality, Methodology Design, Rapid Prototype

\section{Introduction}

In this study, a method to design systematic consulting methodologies is to be proposed by using the instructional design model, which is used in educational technology, in consulting methods. In that education methodology should be different due to rapid growth of ICT], insisted it was hard for small companies to find structural models or structures for improving internal capabilities]. There is purpose to design systems to maximize consulting effect designing consulting methodologies and improve the consulting quality. Instructional design or Instructional System Design that is used in educational technology includes education purpose, goal, method and evaluation activities in instructing. learning procedures in which is the representative application of educational technology . The ISD model used in traditional Instructional System Design has the disadvantage of difficulty of understanding if the

${ }^{*}$ Author for correspondence 
demand of client is thoroughly reflected. Due to this issue, Bichelmeyer and Tripp proposed the Rapid prototype methodology in 1990 that quickly develops final outputs starting from the initial design step. Core factors of the final output are integrated to be made into implementable form in which the final methodology can be proposed in the beginning without completing all development procedures of the methodology to continuously reflect the demand of the client firm. Looking into previous project cases applying the Rapid prototype development methodology in actual projects, the time used in design and development procedures can be reduced, satisfaction of firms on outputs can be enhanced and qualitative level of the output (methodology) can also be increased. Along with this, communication between the consultant and firm is lacked in existing methods until analysis results are deducted after analyzing requirements and level in the firm demand analysis step. There is a trend of considering composition of consulting methodology based on analysis results as the intrinsic duty of consultants. However, it can be said that use of the Rapid prototype is required because sufficient opinion sharing is needed to design firm based methodology by firms participating in the design and development procedures. In this study, empirical research is to be performed on investigation on previous research on Instructional System Design models that have been researched and designed in educational technology aspect, plans of applying this in the consulting market and if satisfaction of firms increases when the Rapid prototype is applied.

\section{Advanced Research}

\subsection{Characteristics and Limitation of the ISD Model}

Traditional education programs have been conducted focusing on lectures of professional instructors or experts of corresponding fields and consulting methodology also has been performed in the form of applying methodology possessed by consultants or consulting organizations on firms. However, instructional system development based on ordinary system theories has been started by instruction designers since the 1970s. If this was education based on contents of previous education, ISD can be seen as proposing a method to design education programs. If unilateral consulting based on methodology was most common even in applying possessed methodology on firms in this aspect, it can be said that there is enough necessity of consulting system development which proposes the method of constructing consulting methodologies.

As several models proposed by education engineers have been used in various education sites, they have developed by reflecting characteristics of each firm. At this time, analysis, design, development, implementation and evaluation steps are sequentially connected in generally used methodologies that the education client must until the last step to know the overall contents. Thus, the client does not know the intention or method of the instruction designer in the procedure of deducting the final output that there is almost no opportunity to state or reflect their own opinion. The basic factors of all Instructional System Design models that have been developed until today have been composed of five steps including analysis, as shown in the Figure 1, design, development, implementation and evaluation. This is considered as the basic model of Instructional System Design which is also called as the ADDIE model using the first letters.

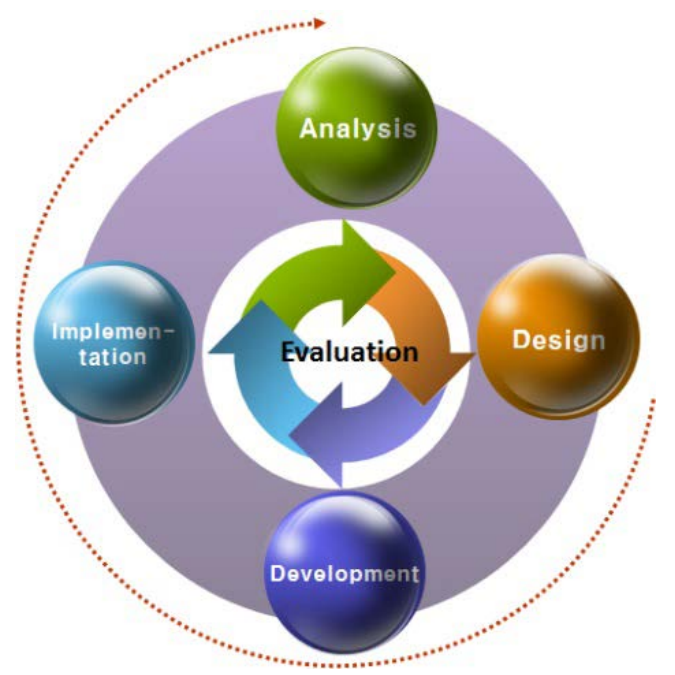

Figure 1. ADDIE model (Gustafson and Branch 2007).

Because of this, Roh (2004) pointed out that 1. Instruction designers are deluded that good programs can be developed without consideration of users, 2. Look on that clients are not aware of their role in program development procedures, and 3. Users and designers do not share thoughts of each other because professionally developed programs are not used by users. 


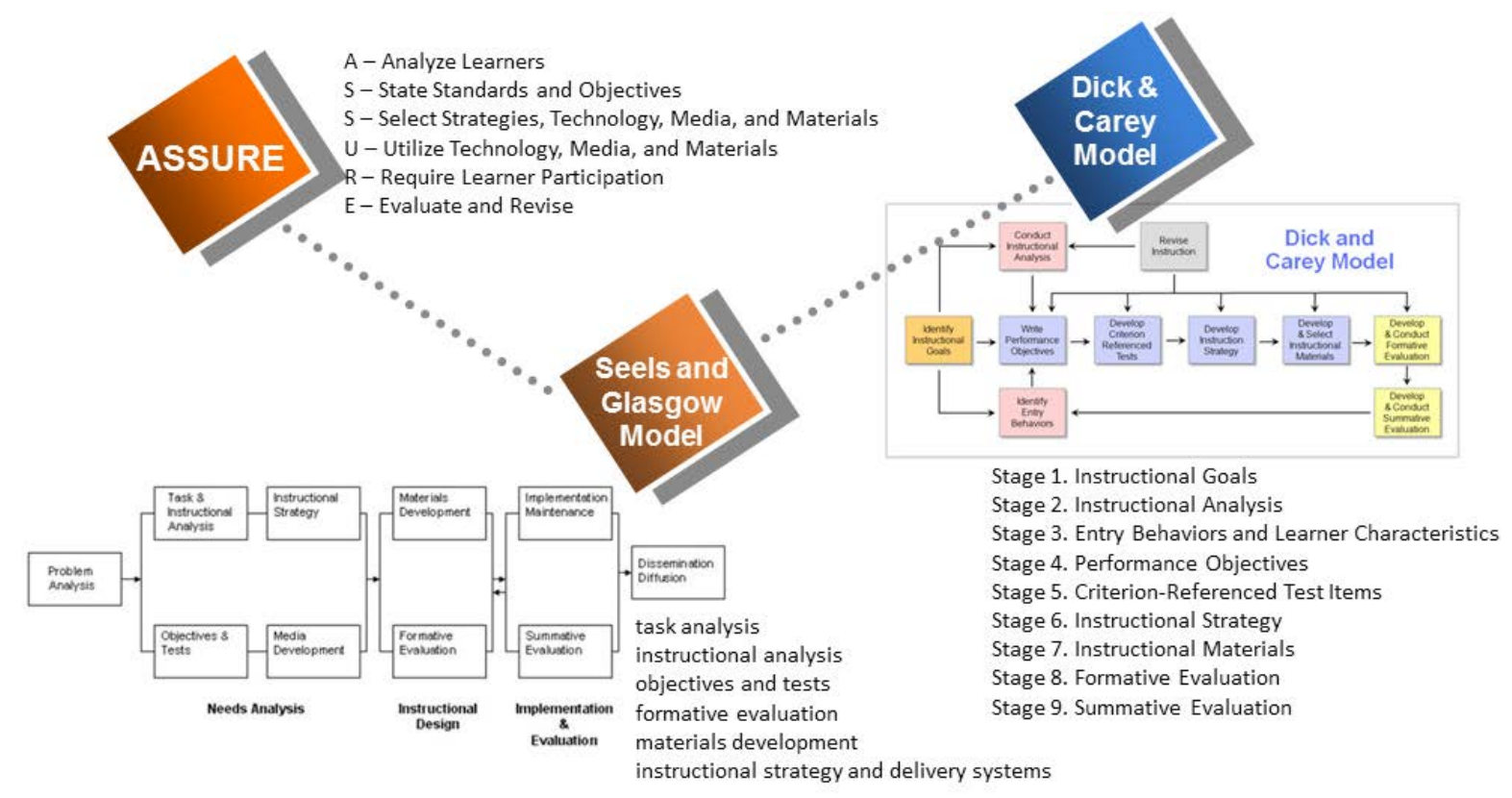

Figure 2. Instructional design model.

This phenomenon is equivalently shown in consulting. Methodologies possessed by consulting organizations or consultants are difficult to be accurately known by firms and there is no opportunity for firms to modify or correct methodologies fitting the situation of that firm. Rather than making optimum methodologies with firms, consulting organizations have had more interest in efficiently applying a particular methodology in firms. Because of this, the meaning and direction of progress of the methodology proposed by the consultant can be known when all consulting processes are almost completed. At this time, firms face severe decline of satisfaction when desired results are not obtained and dissatisfaction on invested time and effort is caused. Issues that firms cannot see results followed by the decision of consultants until final results are presented by consultants and that vague understanding of which aspect should be focused to increase satisfaction of firms have been pointed out. Following this, As shown in the Figure 2, several models have been proposed in which instructional design models can be classified by types into the Heinich, Moldenda, Russell and Smaldino model-ASSURE model which is a classroom oriented model, the Seels and Glasgow model which is an output oriented model, Thef which is a system oriented model and Rapid prototype which is an alternative Instructional System Design.

Each methodology has their pros and cons, but the most suitable model is to be applied in developing and applying consulting methodologies. Therefore, opinions of actual demanders were reflected in the initial step of designing education to verify the research on Rapid prototype development methodology making initial to final outputs and its effect after application in consulting sites.

\subsection{Rapid Prototype Development Methodology}

Rapid prototyping means the process of rapidly developing and evaluating prototypes as shown in the Figure 3. The Rapid prototype development methodology by Jones and Richey (2000) is based on the basic ISD model and shows that each step simultaneously takes place at the same time.

The activity of 'Confirmation of learned content in project level' is continuously shown in the design steps of 'Confirmation of instructional strategy' step (Figure 3). While the role of demanders or clients had high percentage in participation of the analysis step in the existing model, continuous participation can be seen in the Rapid prototype model. Thus, the Rapid prototype model places emphasis on mutual and continuous communication and opinion sharing in which this means that mutual opinion can be sufficiently reflected. As result of using this model, which was proposed by Jones and Richey (2000), in actual Instructional System Design processes, it is reported that the time required deducting results reduced, quality 


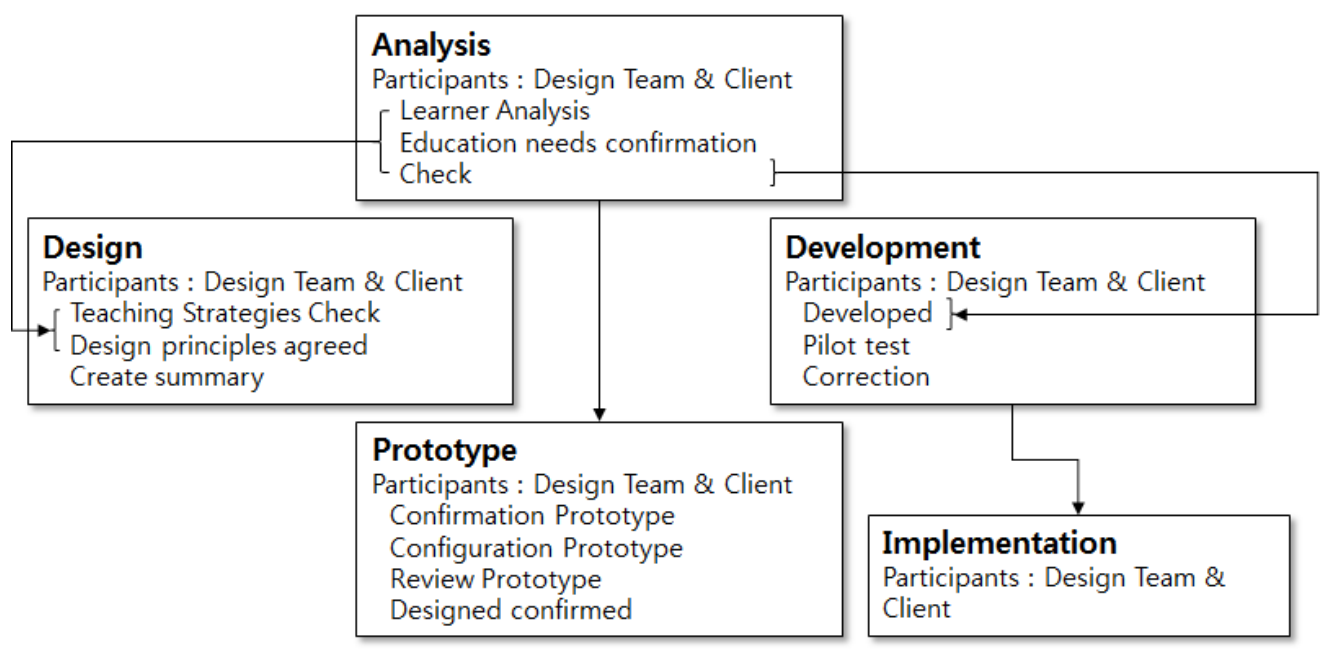

Figure 3. Instructional design model.

of outputs increased and satisfaction increased due to active opinion sharing. Thus, the user in Rapid prototype performs the same role as the developer and has the characteristic of enhancing the completeness of outputs through the process of mutual learning between the developer and user. Therefore, the user has the role as a source by participating in the process of design and has the intrinsic role as a promoter as well. It means that developers can manage professional projects, check actual applicability and perform the role of promoting creating structural discussions with users as well.

This method can also be valuably used in consulting sites and can especially be used in designing and applying consulting methodologies that suit the feature of firms. Unlike the standardized consulting methodologies that consulting organizations possess by listing in department store types, allowing customers to select and applying in a unilateral manner, this is a completely different method. Thus, it means that consulting methodologies customized to firms can be reconstructed based on various methodologies and experiences that consultants possess and this means that a new methodology can be established every time. Application of Rapid prototypes researched in educational technology can very useful in this process. Also, great questions are deducted to focus on the process of finding answers rather than following regulated steps of traditional methodologies by applying the Rapid prototype that it can be called a development of methodology based on process rather than development based on procedures as shown in the Table 1. Thus, it is a process of designing a firm based methodology by emphasizing the procedure of decision making in the methodology design procedure and instead of all procedures of design being separated, they are spirally performed to for ultimate application and increase of satisfaction as well.

Research developing web-based problem focused learning by ${ }^{6}$ was attempted to verify the usability of the Rapid prototype in which analysis, design, prototype development and evaluation, development, implementation and assessment steps are included while analysis activities (data collection, assignment analysis)

Table 1. Waterfall model and Spiral model

\begin{tabular}{ll}
\hline Classic Design (waterfall) Model & Rapid Prototyping (spiral) Model \\
\hline 1. Concept definition & 1. Concept definition \\
2. Requirements definition & 2. Implementation of a skeletal system \\
3. Preliminary design & 3. User evaluation and concept refinement \\
4. Detailed design & 4. Implementation of refined requirements \\
5. Code implementation & 5. User evaluation and concept refinement \\
6. Test and acceptance & 6. Implementation of refined requirements \\
7. [griping because you now realize that there & 7. [etc., etc., in a continuous cycle] \\
was something that got left out back in step 2] & \\
\hline
\end{tabular}


are simultaneously applied in design and prototype development procedures that take place afterwards. Also, high satisfaction on outputs were reported as opinions were stated and demanders participated in the development procedure in which a user based design model was proposed as shown in Figure $4^{6}$.

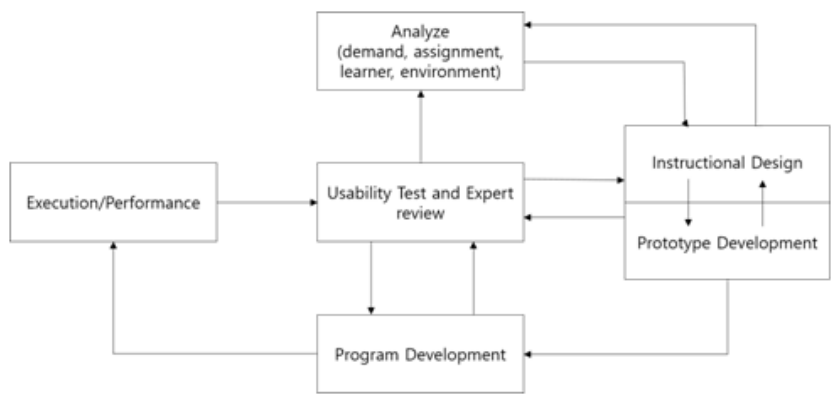

Figure 4. User based design model ${ }^{7}$.

\section{Research Method}

\subsection{Developmental Research Method}

Knowledge created through the consulting site application study of Rapid prototype researched in educational technology can be divided into two categories. First, consulting procedures used in particular situations are described; analyzed and final outputs are evaluated to deduct context-depending knowledge. Second, general analysis is performed on the total procedure of design, development and particular components. In this study, the second exploratory analysis investigating the procedure of design, development, and evaluation is established. Afterwards, Rapid prototype was applied to develop the procedure of specific consulting called "establishment of medium and long term strategy" to design, develop, apply, and apply the consulting methodology while collecting and analyzing the reactions of the people in charge of the firm and activities in that process.

\subsection{Research Subject : Consulting Cases}

This research was subject to 6 domestic small and medium sized companies with sales of fewer than 20 billion won that are participating the government 'Hidden Small Firm Promotion Business', The process of "diagnosis $\rightarrow$ deduct problem $\rightarrow$ suggest solution $\rightarrow$ establish specific plan"has been generally applied in similar consulting sites, but all procedures were being unilaterally provided led by consultants or consulting organizations. Also, the options of firms on specific consulting methodology in deducting problem or suggesting solution steps have been limited. Therefore, to comparatively analyze the effectiveness by application of research methodology subject to similarly sized companies, 2 companies were set at the control group and 4 companies were set as the experimental group to verify the validity of the Rapid prototype.

\subsection{Research Procedure}

Without determining which consulting methodology should be applied before performing consulting on the firm, the procedures applying the Rapid

Table 2. Procedures of development and application of the Rapid prototype applied consulting methodology

\begin{tabular}{|c|c|c|c|c|c|c|c|c|c|c|c|c|c|c|c|}
\hline \multirow{2}{*}{$\begin{array}{l}\text { Development } \\
\text { Step }\end{array}$} & \multirow{2}{*}{$\begin{array}{l}\text { Period(Weeks) Specific } \\
\text { Procedure }\end{array}$} & \multicolumn{11}{|c|}{ Week of Progress } & \multicolumn{3}{|c|}{ Classification of Participant } \\
\hline & & 1 & 2 & 3 & 4 & 5 & 6 & 7 & 8 & 9 & 10 & 11 & Firm & Consultant & Researcher \\
\hline \multirow[t]{3}{*}{ Analysis } & Demand Analysis & $\bullet$ & 1 & $\bullet$ & 2 & 3 & & 5 & 6 & 7 & 8 & 9 & o & o & 6. \\
\hline & Basic Diagnosis & 1 & $\bullet$ & $\bullet$ & 2 & $\bullet$ & & $\bullet$ & 4 & 5 & 6 & 7 & ० & ○ & 7. \\
\hline & Assignment Analysis & 1 & $\bullet$ & $\bullet$ & 2 & $\bullet$ & & $\bullet$ & 4 & 5 & 6 & 7 & o & o & o \\
\hline \multirow{8}{*}{$\begin{array}{l}\text { Design and } \\
\text { Development }\end{array}$} & Methodology Design & 8 & 9 & $\bullet$ & 1 & $\bullet$ & & 1 & $\bullet$ & 1 & 1 & 1 & o & o & 8. \\
\hline & Application of First Prototype & 1 & 2 & $\bullet$ & & & & & & & & & & 0 & 9. \\
\hline & Effectiveness Assessment & 1 & 2 & 3 & $\bullet$ & 4 & 5 & 6 & 7 & 8 & 9 & 1 & ○ & ○ & o \\
\hline & Application of Second Prototype & 1 & 1 & 1 & 1 & $\bullet$ & & $\bullet$ & 1 & 1 & 1 & 1 & 20) & o & 10. \\
\hline & Effectiveness Assessment & 1 & 2 & 3 & 4 & 5 & & 7 & $\bullet$ & 8 & 9 & 1 & ○ & o & o \\
\hline & $\begin{array}{l}\text { Application of Final } \\
\text { Methodology }\end{array}$ & 1 & 1 & 1 & 1 & 1 & & 1 & 1 & $\bullet$ & $\bullet$ & 1 & 20) & ○ & 11. \\
\hline & $\begin{array}{l}\text { Application Effectiveness } \\
\text { Assessment }\end{array}$ & 1 & 2 & 3 & 4 & 5 & & 7 & 8 & 9 & 1 & $\bullet$ & ० & o & o \\
\hline & Decision of Final Prototype & 1 & 1 & 1 & 1 & 1 & & 1 & 1 & 1 & 2 & $\bullet$ & O & o & o \\
\hline
\end{tabular}


prototype development methodology were analyzed. The development and procedure of methodology of consultants participating as designers were observed. To investigate if repetitive and simultaneous methodology development took place as shown in previous educational technology research regarding the application of the Rapid prototype development methodology as shown in the Table 2, consultants wrote daily consulting records. Time used for investment, contents of each step and negotiation with the firm were mainly recorded contents and the problems or improvement points that the consultant felt were reviewed at the beginning, interim report and final report periods. Summarizing the contents recorded by the consultants, the procedures applying the Rapid prototype development methodology were classified and analyzed.

In Table 3 FGI (Focusing Group Interview) was performed with firm employees who continuously participated the development procedure to investigate reaction of firms on the Rapid prototype application. Furthermore, effectiveness evaluation items sensed by the firms were developed in reference to the 'Formative evaluation field for one-to-one evaluation between the instruction designer and learner' proposed by/] Application effectiveness evaluation items on the prototype were composed of 8 categories and 14 items.

Table 3. EFFECTIVENESS EVALUATION ITEMS OF RAPID PROTOTYPE APPLICATION

\begin{tabular}{|c|c|}
\hline Category & Item \\
\hline 1. Goal & $\begin{array}{l}\text { Contents corresponds with overall } \\
\text { composition }\end{array}$ \\
\hline 2. Suitability with & Contents proposed in initial demand \\
\hline Demand Analysis & analysis step are all included \\
\hline 3. Composition of & Overall composition of methodology \\
\hline Methodology & has organization \\
\hline 4. Expression of & Vocabulary and sentences used in \\
\hline Methodology & methodology are easy to understand \\
\hline 5. Understanding & Procedures and contents used in \\
\hline of Procedure and & methodology are easy to understand \\
\hline \multicolumn{2}{|l|}{ Contents } \\
\hline 6. Workload & Workload due to developed \\
\hline & methodology is proper \\
\hline 7. Usability & Developed methodology will have \\
\hline & actual effect in firm \\
\hline $\begin{array}{l}\text { 8. Future Applica- } \\
\text { bility }\end{array}$ & $\begin{array}{l}\text { Developed methodology can be used } \\
\text { in the future }\end{array}$ \\
\hline
\end{tabular}

Lastly, the role of development participants, effectiveness and reality of the Rapid prototype was analyzed based on FGI results with the person in charge of the firm and daily consulting records to find improvement points for the Rapid prototype development methodology.

\section{Experimental Results}

While performing this research, firm executives participated all steps of composing and applying the methodology following basic diagnosis results and experienced main executives were composed as firm experts. Overall composition and goal of consulting methodology was confirmed by the firm and preliminary application was performed in the first prototype as shown in the Table 4. Evaluation on the second prototype was subject to firm employees and firm experts and evaluation on the third prototype was conducted subject to firm experts.

Table 4. EVALUATION RESULTS OF FIRST PROTOTYPE

\begin{tabular}{lcc}
\hline Category & $\begin{array}{c}\text { Firm } \\
\text { Employee }\end{array}$ & $\begin{array}{c}\text { Firm } \\
\text { Expert }\end{array}$ \\
\hline 1. Goal & 4 & 5 \\
2. Suitability with Demand & 4 & 4 \\
Analysis & & \\
3. Composition of Methodology & 3 & 4 \\
4. Expression of Methodology & 2 & 3 \\
5. Understanding of Procedure & 3 & 4 \\
and Contents & & \\
6. Workload & 3 & 3 \\
7. Usability & 5 & 5 \\
8. Future Applicability & 5 & 5 \\
\hline
\end{tabular}

As a result of receiving evaluation on the second prototype by firm employees and firm experts, high satisfaction was shown in suitability of goal, appropriateness of demand, usability and future applicability, but composition of methodology, understanding of procedures and contents and workload were pointed out as disadvantages (Table 5). It was shown that especially firm employees and firm experts all recognized that the methodology to be developed will be very useful in actual application as well. The methodology was evaluated that overall composition and contents were suitable to demands in which this was because methodology was developed through mutual discussion since the initial prototype development procedure and 
the opinions of firm employees were reflected. In the procedure of developing the final prototype, modification was performed to enhance work efficiency and level of understanding composition of methodology, order and time of each applied step, vocabulary and sentences included in the methodology. Evaluation on the third prototype was conducted subject to firm experts and items that showed low satisfaction in the second prototype showed high satisfaction.

Table 5. EVALUATION RESULTS OF SECOND PROTOTYPE

\begin{tabular}{lcc}
\hline Category & $\begin{array}{c}\text { Effectiveness } \\
\text { Evaluation of Second } \\
\text { Prototype }\end{array}$ & $\begin{array}{c}\text { Effectiveness } \\
\text { Evaluation } \\
\text { of Third } \\
\text { Prototype }\end{array}$ \\
\hline 1. Goal & 4.5 & 5.0 \\
2. Suitability with & 4.0 & 5.0 \\
$\begin{array}{l}\text { Demand Analysis } \\
\text { 3. Composition of }\end{array}$ & 3.5 & 5.0 \\
Methodology & & \\
4, Expression of & 2.5 & 5.0 \\
Methodology & & 5.0 \\
5. Understanding & 4.0 & \\
of Procedure and & & 4.0 \\
Contents & 3.0 & 5.0 \\
6. Workload & 5.0 & 5.0 \\
7. Usability & 5.0 & 4.9 \\
8. Future Applicability & 3.9 & \\
Sum & &
\end{tabular}

Summarizing the evaluation results on the effectiveness of the second and third prototype felt by firm experts, high evaluation was given by firms on the fact that their requirements can be continuously requested and that they can participated in reflected procedures. Also, it could be seen that time required by consultants for modification reduced and satisfaction of all participants increased as the project headed toward the end.

Also, it was shown that the satisfaction on overall consulting of the experimental group was $12.5 \%$ higher than the control group firms that applied ordinary consulting methodology following the direction of this research and firm acceptance on overall consulting contents was shown to be $25 \%$ higher. Through this result, it can be seen that continuously accepting firm requirements and supplementing those factors by continuously participating firm employees in methodology development and application procedures in consulting procedures is a significant factor that increases satisfaction on the prototype.

\section{Conclusions}

In this study, the Rapid prototype model which is a type of user based Instructional System Design (ISD) researched in educational technology was applied in consulting sites to investigate the effects. Through analysis, design, development and evaluation steps for 3 months, satisfaction and effectiveness could be increased compared to the control group. Moreover, the important fact is that satisfaction and acceptance have been improved together in the perspective of mutual application by each step through various types of communication and sharing between firms and consultants. Therefore, it could be confirmed that overall consulting quality could be improved when consulting methodology is constructed and applied with the firm instead of applying standardized consulting methodology to firms. However, a few additional research requirements were found through this study.

First, specific development steps are required. It is currently classified into the analysis step, design step and develop step, but specific processes are not composed in each step in which they take place at the same time that consultants require substantial period of training for application. Moreover, the final effect can very even if the Rapid prototype model is applied by specific methodology (e.g. basic diagnosis methodology) that are not regulated yet.

Second, acceptance or satisfaction of the firm through methodology is important in the consulting procedures, but actual consulting effect must be high. However, the Rapid prototype model focuses on the consulting acceptance of firms rather than quality of the final output. Application of the Rapid prototype model may be difficult if the consulting field is very professional or when the gap of knowledge or experience between the client firm and consultant is large.

Third, qualitative evaluation was performed on the evaluation subject and evaluation method on the results applying the Rapid prototype model due to the difficulty of quantization that the results cannot be clearly determined. Even in this study, there were three 
evaluation subjects including consultant, firm employee and firm expert. Of course, evaluation on prototypes by firm employees or firm experts is important in consulting sites. However, it is necessary for the evaluation method and evaluation subject on the second and third prototype to have more subjectivity.

Despite this limitation, the Rapid prototype model which is the main factor that can increase consulting satisfaction and acceptance was applied in this research to investigate the significance and necessity of joint operation between firms and consultants.

Through this study, it was confirmed that the Rapid prototype model can be effectively applied in developing future consulting methodologies that can be applied in firms. Also, required future assignments could be deducted through empirical research. Following this, it is expected that various methodologies can be developed in the process of developing consulting methodologies in earnest based on this research.

\section{Acknowledgment}

${ }^{*}$ This research was financially supported by Hansung University.

\section{References}

1. Memon AA, Mahar JA, Shaikh H. Effectiveness of information and communication technology in teaching methodology: A case study on in-service college teachers of Khairpur. Indian Journal of Science and Technology. 2015 Oct; 8(27):1-6.

2. Chan MI, Ho YY, Sun KM, Soo PY, Yoo YY. Exploratory research on the development of industrial convergence competency model (Convergence DNA) for SMEs. Indian Journal of Science and Technology. 2015 Oct; 8(25):1-11.

3. ChulIm L, Hoon LJ, Joo LD. Educational technology. Korea National Open University Publication; 2011. p. 79-85.

4. Dick W, Carey L, Carey J. The systematic design of instruction. 7th ed. Upper Saddle River, NJ: Person Education, Inc; NY. 2009

5. Lim C, Yeon E. An empirical study on user-centered Rapid prototyping methodology for the development of corporate training programs. 8th Text 2nd ed. Firm Education Research; 2006. p. 27-50.

6. In LC, Gang KM, Jung KY. A study on Rapid prototype development methodology based on printouts to develop web-based lectures. Educational Technology Research. 2005; 21(1):3-28.

7. Educational Engineering. 2010. Available from: https://etcjournal.com/2010/08/22/educational-engineers-the-missing-link-in-innovation/ 